\title{
Do OPT à Teoria das Restrições: avanços e mitos
}

\author{
Fernando Bernardi de Souza \\ Universidade Metodista de Piracicaba - UNIMEP
}

\begin{abstract}
Resumo
Ainda que não mais se possa considerar a Teoria das Restrições (TOC) como uma abordagem efetivamente nova de se gerenciar organizações, o volume de falsos entendimentos acerca do assunto é muito grande. Este artigo tem o propósito de cooperar no sentido de esclarecer alguns aspectos bastante particulares da TOC, mais especificamente relacionados com a sua proposta de programação da produção baseada na capacidade finita dos recursos fabris, denominada de Tambor-Pulmão-Corda (TPC). Concomitantemente, a partir das discussões expostas, este artigo pretende mostrar que a lógica inerente ao TPC não necessariamente é a mesma do já difundido software OPT, assim como mostrar que a aplicação da lógica de programação para frente e para trás no TPC também muitas vezes difere de alguns livros-textos sobre o assunto.
\end{abstract}

Palavras-chave

Teoria das Restrições; Tambor-Pulmão-Corda; OPT; Programação da Produção.

\section{From the OPT to the Theory of Constraints: advances and myths}

\begin{abstract}
Although Theory of Constraints (TOCJ is a relatively new approach for organizational managing, there is a lot of misunderstanding regarding this subject. In order to shed some light on particulars TOC production aspects concerning to its finite capacity scheduling proposal named as Drum-Buffer-Rope [DBR], this article aims to discuss that the DBR logic is not necessarily the same as that one known as OPT software as well as backward and forward scheduling definitions can be different from that presented in the literature.
\end{abstract}

Key words

Theory of Constraints; Drum-Buffer-Rope; OPT; Production Scheduling. 


\section{INTRODUĈ̣̃O E JUSTIFICATIVA}

É frustrante, por mais que se procure informar o público interessado no assunto, observar a confusão que se faz entre o software de programação da produção denominado OPT (Optimum Production Technology) e a TOC (Theory Of Constraints). O trabalho de Spencer \& Cox (1995) teve justamente este objetivo. Naquele estudo, os autores demonstraram que a TOC é muito mais que um software de programação baseado em capacidade finita dos recursos, compondo, na realidade, diversos aspectos relacionados à:

- Logística: cinco passos do processo de focalização, análise V-A-T, Tambor-Pulmão-Corda, Gerenciamento do Pulmão;

- Processos de Raciocínio como método de solução de problemas: Árvore da Realidade Atual, Diagrama de Dispersão de Nuvem, Árvore da Realidade Futura, Árvore de Pré-requisitos e Árvore de Transição;

- Sistema de Desempenho: Ganho, Inventário, Despesa Operacional, cálculo de mix de produção, Ganho-Dinheiro-Dia, Inventário-Dinheiro-Dia.

Uma adequada atualização do assunto também relacionaria novos conhecimentos relacionados a Marketing (BLACKSTONE JR, 2001), Distribuição (GOLDRATT et al., 2000; YUAN et al., 2003; PTAK \& SCHRAGENHEIM, 2004), Gestão de Projetos (GOLDRATT, 1998; STEIN, 2000), Gestão da Cadeia de Suprimentos (GOLDRATT et al., 2000; UMBLE \& UMBLE, 2002; PTAK \& SCHRAGENHEIM, 2004; SIMATUPANG et al., 2004), dentro outros.

Outro tipo de confusão, também bastante comum de se encontrar na literatura, é considerar OPT como sinônimo da abordagem para programação da produção atualmente proposta pela TOC. Desmistificar este outro engano é uma das finalidades deste artigo. Pretende-se, como foco deste trabalho, mostrar como a TOC evoluiu em termos de propostas para programação de produção, não mais podendo, portanto, ser vista como sinônimo do método proposto no OPT.

Em síntese, este artigo, a partir de um forte detalhamento dos mecanismos propostos pela TOC para programação da produção, busca atender quatro objetivos:

a) Contribuir para uma melhor compreensão da abordagem Tambor-Pulmão-Corda para programação da produção;

b) Mostrar que a lógica proposta pela TOC não é mais um conjunto de procedimentos heurísticos "guardado a sete chaves";

c) Demonstrar que a solução da TOC atualmente aceita para programação da produção já não é mais sinônimo de OPT; d) Demonstrar que os procedimentos atualmente sugeridos pela TOC não são exatamente o que muitos entendem ser, principalmente no que concerne à lógica de programação para frente e para trás.

Para que tal proposta seja alcançada, faz-se necessário apresentar em detalhes o método Tambor-Pulmão-Corda de programação da produção da Teoria das Restrições.

\section{FUNDAMENTOS DA ABORDAGEM TAMBOR-PULMÃO-CORDA}

A TOC sugere uma metodologia para planejamento e controle da produção denominada Tambor-Pulmão-Corda (TPC), do inglês Drum-Buffer-Rope (DBR). Segundo Umble \& Srikanth (2001), a maneira TPC de programar a produção parte do pressuposto de que existem apenas alguns poucos recursos com restrição de capacidade (RRCs) que irão impor o índice de produção da fábrica inteira (Tambor). Para garantir que a produção do RRC não seja interrompida por falta de peça, cria-se na frente dele um inventário que o protegerá contra as principais interrupções que possam ocorrer dentro de um intervalo predeterminado de tempo (Pulmão de Tempo). Com o objetivo de impedir que haja um aumento desnecessário nos níveis de estoque em processo, o material é liberado para a fábrica no mesmo ritmo com que o recurso restritivo o consome (Corda), mas com uma defasagem no tempo equivalente ao pulmão de tempo estabelecido.

Existem muito poucos lugares que devem ser protegidos num sistema cujo fluxo de material é controlado de acordo com os princípios da TOC. Segundo Goldratt (1990), existem somente três tipos de pulmões de tempo. $\mathrm{O}$ primeiro resulta da necessidade de se proteger as restrições de recurso, evitando-se que seu trabalho seja interrompido. Surge, assim, o Pulmão de Recurso. A origem deste pulmão é a área localizada à frente do RRC e conterá estoques de material em processo.

Outro tipo de restrição que deve ser protegida é a restrição de mercado, pois se pretende sempre entregar no prazo. Para isto, necessitar-se-á de um Pulmão de Mercado, ou Expedição, refletido e posicionado nos armazéns de produtos acabados.

No entanto, não são apenas as restrições de recurso ou mercado que necessitam de pulmões. Se o intuito é explorar a restrição, deve-se evitar que peças produzidas por um recurso restritivo fiquem esperando, na operação de montagem, por peças provenientes de recursos nãorestrição. Estabelece-se, então, o Pulmão de Montagem, que deverá conter apenas peças que passaram por recursos não-restritivos.

Segundo Goldratt (1990), deve-se salientar que o 
método TPC possibilita uma programação implícita de todos os recursos não-restritivos da empresa. Aqueles situados antes do RRC deverão processar o mais rápido possível os materiais advindos da primeira operação (controlados pela Corda), de acordo com a ordem de chegada destes. Uma vez que tais recursos possuem excesso de capacidade em relação ao RRC, eles não deverão ter dificuldades para seguir o programa. Da mesma forma, os recursos não-restritivos localizados no roteiro de produção após o RRC estarão diretamente sob o controle deste, pois receberão apenas as peças liberadas pelo RRC. Como tais recursos têm folga no programa, não deverá haver nenhum problema também neste ponto. Logo, ordens de produção explícitas são necessárias apenas em alguns pontos específicos, como nos RRCs e nos locais de liberação de material para a fábrica, por exemplo. A Figura 1 ilustra uma situação fictícia de uma fábrica sincronizada segundo o método TPC. Deve-se reparar que alguns poucos recursos têm suas operações programadas.

A TOC vem procurando demonstrar e convencer as comunidades acadêmica e empresarial de que sua proposta para programação e controle da produção, denominada de Tambor-Pulmão-Corda (TPC), pode alcançar excelentes resultados práticos mesmo quando sua imple- mentação não vem acompanhada por um sistema computacional especializado em programação da produção baseada na capacidade limitada dos recursos, como o OPT. A despeito deste fato, de alta relevância, algumas situações particulares quase que impõem o apoio de um sistema computacional. Fábricas muito balanceadas, onde pequenas oscilações no mix de produtos levam a alterações na localização dos recursos gargalos, são exemplos de situações que tornam imperativo o uso de um sistema computacional especialista.

No tópico que se segue, procurar-se-á apresentar a proposta atualmente aceita pela TOC para sistemas computacionais focados no método TPC. Com o desenvolvimento dos conceitos, espera-se alcançar os objetivos anteriormente mencionados para este estudo.

\section{O MÉTODO TAMBOR-PULMÃO-CORDA NO CONTEXTO DE UM SISTEMA INFORMATIZADO}

Para a TOC, uma das principais condições necessárias à sobrevivência de uma empresa com fins lucrativos é obter dinheiro hoje e sempre, a qual pode ser traduzida como a busca constante pelo controle e melhoria de três

Figura 1: Datas de liberação de material de acordo com as datas dos pedidos e do Tambor. Adaptado de Goldratt (1990).
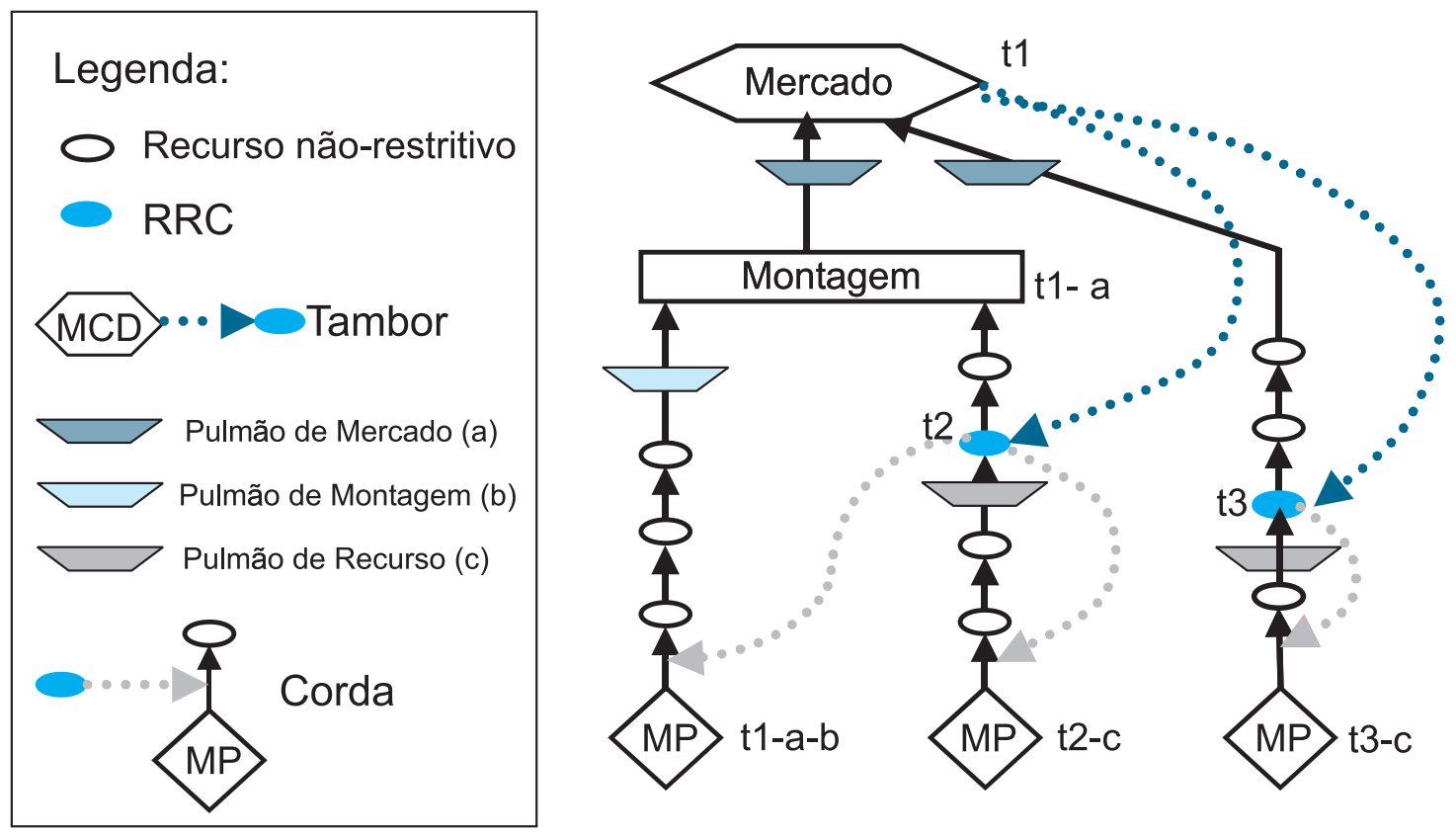
indicadores de desempenho (GOLDRATT \& COX, 1986; GOLDRATT \& FOX, 1989; GOLDRATT, 1990):

Ganho: índice pelo qual o sistema gera dinheiro através das vendas;

Inventário: todo o dinheiro que o sistema investe em coisas que um dia ele pode vender;

Despesa Operacional: todo o dinheiro necessário para transformar inventário em ganho.

Aumentar o Ganho, reduzindo simultaneamente o Inventário e a Despesa Operacional deveria ser o objetivo de qualquer empresa.

A crença fundamental da TOC é que todo sistema constituído com uma meta definida deve possuir ao menos um componente que limita seu desempenho em relação àquela meta. Se assim não fosse, a empresa teria uma lucratividade infinita. Tal componente é definido pela TOC como "restrição" do sistema. Também, esses mesmos sistemas, por se constituírem num conjunto de variáveis dependentes, deverão ser sempre limitados por um número pequeno de restrições. Nesse sentido, a TOC propõe que toda organização deve seguir os seguintes passos como parte de um processo de melhoria contínua (GOLDRATT \& COX, 1986; GOLDRATT \& FOX, 1989; GOLDRATT, 1990):

1. Identificar a restrição do sistema;

2. Explorar ao máximo a restrição do sistema;

3. Subordinar todo o resto à política de exploração da restrição;

4. Elevar a restrição do sistema;

5. Voltar ao primeiro passo, evitando que a inércia das políticas atuais se torne uma restrição.

O desenvolvimento do método TPC, incluindo seu procedimento automatizado, segue exatamente as três primeiras etapas deste processo. Deve-se ter em mente, no entanto, como pressuposto ao que será a seguir apresentado, que não há restrições políticas ou procedimentais à implementação do método.

\section{Identificando as primeiras restrições do sistema}

Para Goldratt (1990), a única forma de se obter um plano de produção verdadeiramente realista é levar em consideração as restrições do sistema durante todo o desenvolvimento do programa. Primeiramente, deve ser reconhecido que o mercado ou os pedidos individuais dos clientes sempre poderão ser considerados como restrição, mesmo quando existirem gargalos de produção.

Assumindo o mercado como a primeira restrição de qualquer empresa, deve-se procurar identificar possíveis restrições adicionais, isto é, recursos sem capacidade suficiente para atender a demanda neles imposta.

A identificação de um recurso-gargalo pressupõe a existência de uma escala de tempo, ou seja, um recurso possui ou não capacidade suficiente de atendimento da demanda em um determinado horizonte de programa. Para verificar se há um verdadeiro gargalo, deve-se calcular a carga total, gerada pelos pedidos que deveriam ser trabalhados durante o horizonte de programa, imposta em cada um dos tipos de recursos. Como um pedido que deve ser entregue após o horizonte de programa pode colocar uma carga dentro do programa, Goldratt (1990) afirma que, no cálculo de carga-máquina, devem-se considerar todos os pedidos que, com certeza, deverão ser feitos dentro do horizonte. Como a restrição de mercado deve ser protegida por um pulmão de mercado, qualquer pedido, cujo prazo seja anterior ao horizonte do programa mais o pulmão de mercado, deverá colocar sua carga sobre os recursos da empresa dentro do horizonte.

Outro aspecto a ser considerado no cálculo de cargamáquina refere-se aos estoques existentes. $\mathrm{O}$ cálculo de carga deve ser feito a partir da explosão de pedidos segundo a estrutura dos produtos, levando-se em conta todos os estoques existentes, materiais em processo e produtos acabados.

\section{$\triangle$ TOC é muito mais que um software de programação baseado em capacidade finita dos recursos.}

Ainda no estágio de identificação das restrições da empresa, devem-se considerar também os tempos de preparação de máquinas. Neste ponto, segundo Goldratt (1990), não se deve pressupor que pedidos diferentes para o mesmo tipo de peça/operação devem ser feitos em um único lote. A definição do tamanho do lote de produção deve ser o resultado do programa e, portanto, não pode ser predeterminada neste estágio. Assim, para o cálculo de carga-máquina, deve-se considerar, no mínimo, uma preparação por tipo de peça/operação.

Uma vez calculada a carga para cada tipo de recurso, tem-se que comparar este valor com a disponibilidade de tempo dos recursos calculada no mesmo intervalo de tempo, considerando-se o número de unidades disponíveis de cada tipo de recurso e de acordo com o calendário da empresa. Se a carga colocada em um recurso for maior que sua disponibilidade, ter-se-á um recurso-gargalo. Se mais de um recurso apresentar uma disponibilidade de 
tempo inferior a sua carga, deverá ser considerado como recurso restritivo, ou mais precisamente, como Recurso com Restrição de Capacidade (RRC), aquele que estiver mais sobrecarregado.

\section{Explorando a restrição: desenvolvendo o Tambor}

Uma vez identificada a existência de um RRC, ou seja, a empresa não possui capacidade suficiente para atender a todos os pedidos nos seus respectivos prazos, deve-se partir para a etapa de exploração da restrição. Em outras palavras, deve-se tirar o máximo deste recurso. Há diversas ações que podem derivar desta decisão:

- Evitar que o RRC fique parado durante viradas de turno;

- Garantir, via inspeção rigorosa, que o RRC não processe peças defeituosas oriundas de processos antecedentes;

- Garantir que os processos de fabricação do RRC, e posteriores a ele, estejam sempre dentro das especificações;

- Focalizar esforços de manutenção preventiva e prioridade na manutenção corretiva no RRC;

- Programar o recurso de forma que este processe os itens mais lucrativos para a empresa;

- Programar o recurso de forma a ocupar, da melhor maneira possível, seu tempo disponível, levando-se sempre em consideração os prazos de entrega dos pedidos.

Em consonância com o ponto de vista de desenvolvimento de um programa de produção, o foco deste tópico será, precisamente, mostrar o que o sistema TPC sugere quanto à última ação anteriormente citada.

Esta etapa de exploração do RRC, que também pode ser entendida como a subordinação do RRC à exploração da restrição mercado, implica em gerar um programa de produção para o RRC de maneira que todo seu tempo disponível seja utilizado da melhor maneira possível ao propósito da empresa toda. O processo de exploração do RRC pode ser dividido em vários passos, assim especificados:

Passo1: Como já dito, primeiramente, devem-se considerar todos os pedidos cujos prazos sejam anteriores ao horizonte do programa mais o pulmão de mercado. Conhecido o volume de pedidos a serem atendidos, deve-se calcular a carga de produção no RRC, expressa no segundo passo.

Passo 2: Calcular a quantidade de peças que o RRC deve produzir de cada pedido a partir de sua estrutura de produto, rendimento, estoque em processo e produtos acabados. Estes últimos devem ser distribuídos segundo as datas requeridas dos pedidos. Com estes dados em mãos, parte-se ao passo seguinte.

Passo 3: Calcular o montante de carga imposto no RRC a partir do tempo requerido para processar uma unidade do produto e do tempo de preparação. Tal cálculo é bastante simples, mas aqui não basta saber quanto fazer ou por quanto tempo o RRC estará produzindo para satisfazer determinado pedido. É necessário também determinar quando aquelas unidades serão produzidas, o que remete ao próximo passo.

Passo 4: Colocar as tarefas do RRC numa linha de tempo, onde o RRC deve completar sua tarefa no instante equivalente a um pulmão de expedição antes do prazo do pedido. Repetindo-se este cálculo para todos os pedidos que necessitam do RRC, o sistema deve posicionar as tarefas, aqui chamadas de blocos, no eixo do tempo do recurso. A distribuição dos blocos ao longo do eixo do tempo deve ser feita segundo os prazos dos pedidos, começando pelo pedido a ser entregue primeiro.

Como cada bloco foi gerado sem levar em consideração, até aqui, as limitações de capacidade do RRC, estes blocos podem se empilhar um sobre o outro, formando uma espécie de quadro de ruínas, como denominado por Goldratt (1990) e mostrado na Figura 2.

Supondo que a Figura 2 represente uma situação onde o RRC é composto por dois recursos do mesmo tipo (o RRC deve ser entendido, portanto, como um conjunto de recursos do mesmo tipo), pode-se esperar que o RRC processe até duas tarefas (ou blocos) por vez. Deve-se, portanto, nivelar as ruínas de modo que o número de blocos sobrepostos seja, no máximo, igual ao número de

Figura 2: Quadro de ruínas representando a distribuição das tarefas necessárias para o RRC atender a todos os pedidos no prazo.

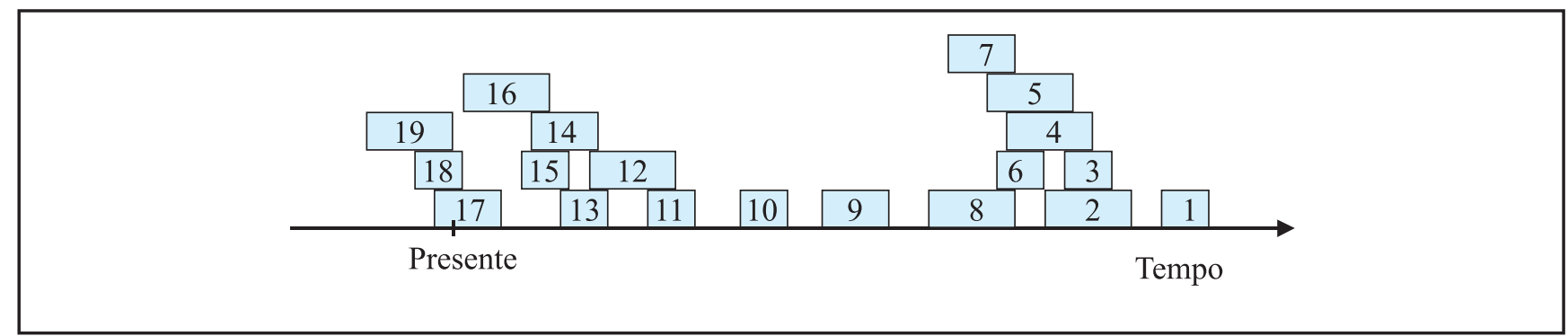

Fonte: Goldratt (1990). 
recursos do mesmo tipo que definem o RRC, ou dois blocos sobrepostos, segundo a situação exemplificada.

Passo 5: Nivelar a ruína segundo a quantidade de recursos disponíveis implica em deslocar os blocos. Há duas possibilidades neste ponto: deslocar para a direita ou para a esquerda.

Como deslocar para a direita significa consumir o pulmão de mercado estabelecido, o que colocaria em risco o Ganho da empresa, Goldratt (1990) sugere que tal deslocamento seja feito para a esquerda. Ainda que deslocar para esquerda signifique antecipar a realização de um pedido o que, por sua vez, implica em aumentar os estoques, a TOC sugere que, sempre que a escolha for entre perder Ganho e aumentar Inventário, deve-se optar por aumentar o Inventário.

Assim, o sistema deve redistribuir os blocos movendo-os para a esquerda, porém, mantendo a ordem, ou seqüência original, ou seja, se determinado bloco estiver com sua face direita após (mais tarde) a face direita de outro bloco, após o deslocamento dos blocos tal posição relativa deverá ser mantida. A Figura 3 apresenta o quadro de ruínas com os blocos nivelados.

Este nivelamento inicial, entretanto, muito provavelmente não terá eliminado todos os conflitos com a rea- lidade. Sendo este RRC um recurso sem capacidade suficiente para atender a todos os pedidos, é natural que conflitos sempre existirão. Após o primeiro nivelamento dos blocos, o novo conflito deverá estar refletido na forma de tarefas (blocos) a serem executadas no passado. Surge, desta forma, a necessidade de um próximo passo.

Passo 6: Reprogramar para o Tempo Zero, empurrando-se os blocos para a direita, até o ponto onde nenhum pedido tenha que ser trabalhado no passado. Neste momento, ao se deslocar os blocos para a direita (ver Figura 4), alguns pedidos deverão estar à direita de sua posição inicial. Isto significa que as datas dos pedidos correm risco de não serem atendidas. Os passos seguintes procuram considerar esta questão.

Passo 7: Após efetuados os passos 5 e 6, alguns pedidos ficaram localizados à direita de sua posição original. Os blocos cujos deslocamentos foram superiores à metade do pulmão, serão considerados problemas (grandes riscos de terem seus prazos não cumpridos) e serão coloridos de vermelho (ou simplesmente marcados pelo sistema). Goldratt (1990) sugere que tarefas cujos atrasos forem inferiores à metade do pulmão de mercado são gerenciáveis, ou seja, se focadas pela gerência, poderão ainda ser finalizadas no prazo. E quanto

Figura 3: Quadro de ruínas sem o conflito de blocos sobrepostos acima do número de recursos disponíveis.

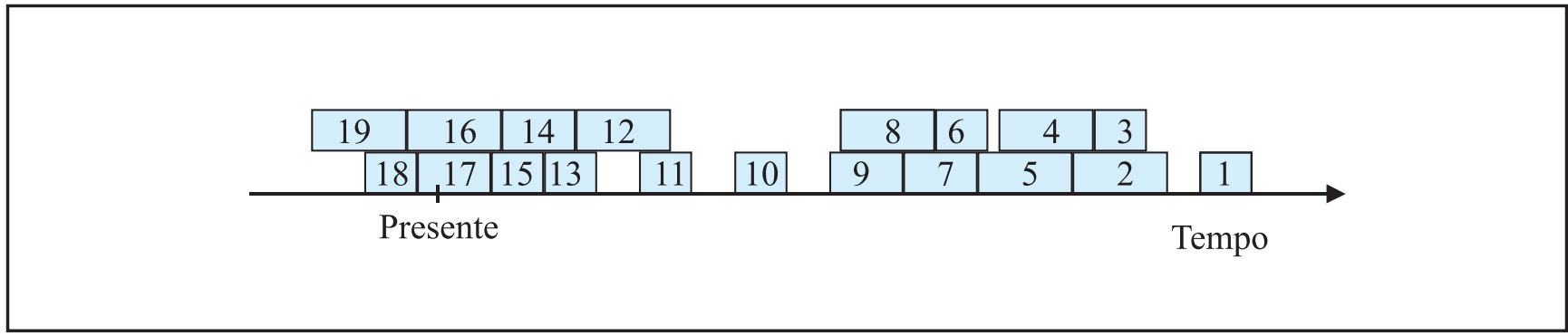

Fonte: Goldratt (1990).

Figura 4: Quadro de ruínas sem o conflito de blocos localizados no passado.

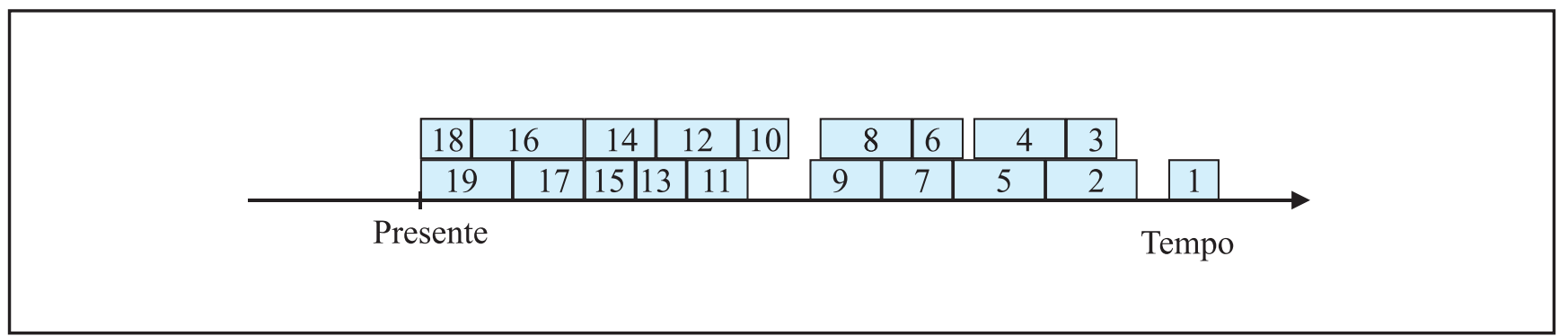

Fonte: Goldratt (1990). 
às tarefas cujos atrasos foram superiores à metade do pulmão de mercado? A estas tarefas, que o sistema coloriu de vermelho, Goldratt (1990) sugere os passos

Passo 8: Reseqüenciar os blocos segundo a presença de material disponível antes da restrição para executá-los e identificar novos blocos vermelhos. Antes de qualquer tentativa de melhorar a situação apresentada pelo último quadro, Goldratt (1990) afirma ser este o momento para identificar se há, de fato, material disponível para que as tarefas, como apresentadas até agora, possam ser efetivamente realizadas. Um material pode ser considerado como disponível para a realização do programa no RRC quando houver um tempo equivalente a mais da metade do pulmão do RRC (de preferência dois terços) para trazê-lo do ponto onde se encontra até a origem do pulmão, ou seja, no RRC. Se demandar um tempo maior que isso, os blocos devem ser reseqüenciados de forma a eliminar qualquer conflito com a disponibilidade de materiais. seguintes.

na os tamanhos dos lotes de produção. Deve-se economizar ao máximo com preparações de máquinas no RRC, porém, devem-se evitar supostas economias com preparação que não implicam em vantagens quanto ao Ganho da empresa. Fica evidenciado também que a TOC não faz uso de nenhum método baseado nos conceitos de lotes econômicos no momento de decidir pelo dimensionamento de seus lotes de produção.

Esgotadas todas as possibilidades de economias com preparação, devem-se partir para uma nova possibilidade, o uso de horas-extras, expressa no passo seguinte.

Passo 10: Fazer uso de horas-extras e/ou descarregar a carga para outros recursos não-restrição e rever os blocos vermelhos. A permissão pelo uso de horas-extras em uma determinada data beneficia não apenas os blocos programados para o final desta data, mas também todos os outros blocos a serem executados depois, pois tudo poderá ser executado antes do planejado. Isto implica que a hora-extra deve ser usada de preferência em uma data anterior ao primeiro bloco vermelho. Como o uso de hora-extra implica também em aumento de inventário, é conveniente que esta seja aplicada não apenas à esquerda do primeiro bloco vermelho, mas o mais próximo deste.

Passo 11: Para os blocos que

Passo 9: Aglutinar blocos iguais para se economizar em preparação e, assim, conseguir mais tempo produtivo para a restrição; rever os blocos vermelhos. Os blocos até aqui gerados foram obtidos a partir de informações provenientes das necessidades dos pedidos sem, porém, considerar-se a situação onde pedidos distintos se referem à mesma peça/operação.

Quando tais blocos existem, há a possibilidade de se ganhar tempo com preparação do RRC. Sendo este RRC um recurso-gargalo, tais economias de preparação liberam capacidade para que o RRC possa atender um volume maior de pedidos dentro do mesmo intervalo de tempo, aumentando o Ganho da empresa. Por outro lado, antecipar a realização de uma tarefa para se ganhar em preparação implica, também, em aumento no estoque. Novamente, o aumento no Ganho deve ter prioridade sobre o aumento do Inventário.

Alguns aspectos devem ser destacados aqui. Se for verificado, ao se tentar aglutinar dois blocos idênticos, que após o último bloco candidato a ser antecipado não existe nenhum bloco vermelho, não há por que se optar pela aglutinação, economizando preparação, pois tal "economia" elevaria os estoques sem nenhum impacto positivo no Ganho da empresa.

Esta questão deixa claro o modo como a TOC determi- permanecem vermelhos, mesmo depois de tomadas as medidas anteriores, redefinir novos prazos dos pedidos com os clientes. O prazo de cada pedido que criou um bloco vermelho deve ser adiado. Este novo prazo deve ser igual ao prazo do bloco vermelho correspondente mais o pulmão de expedição. O que mais importa neste ponto, entretanto, é a possibilidade de o usuário poder identificar pedidos cuja probabilidade de atendimento no prazo é mínima e renegociar com o cliente com antecedência, antes que o fato se consume.

Para Goldratt (1990), a seqüência de passos apresentada completa a primeira tentativa de construção do que é geralmente chamado de programa-mestre. Para a TOC, entretanto, este programa difere do conceito tradicional de programa-mestre, pois é criado não apenas a partir de dados relativos aos pedidos, mas também a partir das considerações de limitação da capacidade do RRC.

De tudo o que aqui foi apresentado como forma de se criar um programa para o RRC (Tambor), deve-se notar que os procedimentos sugeridos em nada se parecem com as técnicas tradicionais de programação para frente (forward) ou para trás (backward).

\section{Subordinando os demais recursos}

A identificação de uma restrição inicial e a elaboração 
do Tambor não implica na inexistência de outras restrições de recurso. O processo final de elaboração de um programa da produção para a fábrica inteira termina somente quando, após o passo de subordinação dos demais recursos ao programa da(s) restrição(ções) identificada(s), todas as restrições da empresa forem identificadas e exploradas. Aqui, subordinar deve ser entendido como a exigência de que todos os recursos acompanhem o ritmo do Tambor. Se após a etapa de subordinação houver choques com a realidade (como, por exemplo, a necessidade de se liberar material no passado) e tais choques não puderem ser resolvidos, então uma nova restrição foi identificada e esta, juntamente com a primeira, deverá ser explorada e novamente subordinada.

Goldratt (1990) comenta que a etapa de subordinação muitas vezes traz uma situação curiosa. Como um recurso, com aparente folga de capacidade em relação à restrição inicial, não é capaz de acompanhar o ritmo desta, nem mesmo fazendo uso de artifícios como hora-extra? Para o autor, tais recursos apresentam, após a etapa de subordinação, conflito com o tempo, e não conflitos de carga versus disponibilidade de capacidade. Como então abordá-los?

Segundo Goldratt (1990), todo processo de subordinação (ver Figura 1) está baseado na subtração de vários pulmões das datas estabelecidas no Tambor, não se levando em conta, portanto, a capacidade dos recursos nãorestritivos. Existiria, porém, uma relação entre capacidade e tamanho dos pulmões?

Para o autor, um dos fatores determinantes para o dimensionamento dos pulmões é a disponibilidade não imediata de um recurso não-restritivo. Quando uma determinada tarefa chega para ser processada por um recurso e este está trabalhando em outra ordem (podendo ainda haver outras tarefas na fila de espera), aquela deve esperar até que chegue sua vez. Este tempo na fila é definido como disponibilidade não imediata de um recurso e acaba por ser, em muitas situações, dominante para o tamanho dos pulmões. Nestes casos, tempos de processamento, movimentação e preparação de máquinas corresponderiam a uma parcela menos significativa que a disponibilidade não imediata dos recursos para o lead time total.

A Figura 5 ilustra a situação descrita, onde certo recurso não-restritivo, apesar de possuir, na média, capacidade suficiente para atender às ordens de fabricação de um determinado período, possui picos de carga que acabam por atrasar o fluxo daquelas ordens.

Uma vez que aqui se está lidando com recursos nãorestritivos, deve sempre haver "vales" suficientes para absorver os picos de carga. Há, no entanto, que se considerar a direção na qual os picos devem procurar os vales. Se o deslocamento dos picos buscar vales no futuro (à direita, portanto), as datas dos pedidos talvez tenham que ser postergadas, o que afetaria o Ganho. A única maneira efetiva de se padejar (deslocar) picos aos vales é deslocando-os para a esquerda, retrocedendo no tempo. A lógica aqui é a mesma utilizada quando da elaboração do Tambor, ou seja, aceita-se pagar com um aumento no inventário às custas de se evitar perdas de Ganho.

Figura 5: Recurso não-restritivo com pico de carga ou com disponibilidade não imediata.

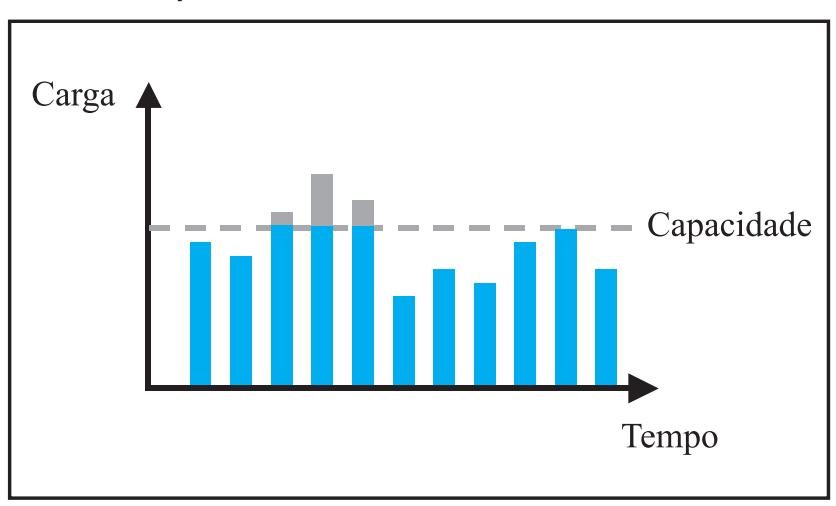

Goldratt (1990) sugere, no entanto, que padejar picos aos vales sempre à esquerda remete à questão da elaboração de um procedimento que de fato permita um real retrocesso no tempo. Deve-se deslocar os picos de carga para o passado de forma a garantir que as cargas resultantes possam ser feitas por todos os recursos.

Para o autor, nenhuma operação deve ser programada para certa data até que todas as outras que necessitam ser programadas em uma data posterior já tenham sido programadas. Esta seria a única forma de se garantir que, ao se padejar um pico de carga para uma data no passado, suas operações de alimentação também encontrarão um vale, ao invés de um outro pico. Tudo isto, salienta o autor, deve ser feito ainda durante a fase de elaboração do programa para os recursos não-restritivos, e não após, como o fazem os sistemas MRPII (Manufacturing Resources Planning).

Para o autor, a lógica de programação para trás (backward scheduling) dos sistemas MRPII falham neste aspecto e, por isso, não conseguem sugerir programas confiáveis. Para Goldratt (1990), os sistemas MRPII não são capazes de padejar convenientemente os picos de carga dos recursos ainda durante a fase de programação, pois estes não permitem um efetivo e consistente retrocesso no tempo. O autor faz uso de um exemplo para demonstrar isso. Suponha-se que a estrutura de um 
produto (bill of material) seja formada por um produto composto por uma montagem de duas peças. Para este produto, têm-se muitos pedidos com diferentes prazos. Como o MRPII faria a programação neste caso?

Primeiramente, para garantir que os estoques de material em processo atualmente presentes sejam distribuídos para os pedidos mais urgentes, o sistema deve começar com o primeiro pedido. Depois o MRPII deve explodir as necessidades segundo a estrutura do produto. Ele primeiro alcança a montagem e escolhe uma das duas peças que devem ser produzidas. Escolhendo uma delas o sistema retrocede no tempo até atingir a necessidade de material daquela peça. E a outra peça? Agora o sistema deve voltar à montagem e seguir a ramificação da segunda peça. O problema aqui é que, ao voltar para a operação de montagem, o sistema deixou de retroceder no tempo. Na verdade ele avançou no tempo. Descendo ao nível do material necessário à segunda peça, o sistema volta a retroceder no tempo. Finalizado este pedido, o sistema deve buscar o próximo pedido, pedido este a ser feito após o primeiro. Logo, mais uma vez, o sistema deixou de retroceder e voltou a avançar no tempo.
Para um melhor entendimento do processo de subordinação, faz-se necessário apresentar dois conceitos de fundamental importância: pulmões dinâmicos e capacidade protetora.

\section{Os conceitos de Capacidade Protetora e de Pulmão Dinâmico}

Goldratt (1990) afirma que se devem evitar ao máximo as restrições interativas ou secundárias, isto é, todos os recursos não-restritivos devem ter mais capacidade do que está estritamente prevista pela carga esperada. Assim, se o objetivo é explorar o RRC, deve-se ter algum inventário antes dele para se proteger o Ganho. Entretanto, quando ocorre alguma interrupção no fluxo de material ao RRC, esta consome parte do inventário colocado a sua disposição e, se tal interrupção voltar a ocorrer, a restrição poderá ficar exposta.

Torna-se vital, portanto, que o inventário colocado na frente da restrição seja reconstruído antes que uma nova interrupção venha a acontecer. Para isto, porém, todos os recursos não-restritivos devem ser capazes de processar material mais rapidamente que o estritamente pedido pelo índice de consumo da restrição. Os demais recursos devem ser capazes de fornecer o que a restrição precisa e ainda reconstruir o inventário protetor. Isto é, se houver flutuações estatísticas (quebras, refugos, retrabalhos, variações em torno do tempo de ciclo padrão, etc.), todos os outros recursos devem ter mais capacidade que o estritamente pedido pela demanda para se poder explorar a restrição. Desta forma,

Esta sistemática de retrocesso e avanço no tempo realizado pelos procedimentos de cálculo dos sistemas tipo MRPII não é entendido pela TOC como retrocesso no tempo ou programação para trás. Para a TOC, a única forma de se resolver efetivamente os problemas de picos de carga é desenvolver um procedimento que consistentemente retroceda no tempo. Para isso, tem-se que, primeiramente, distribuir os estoques, porém não mais aqueles localizados entre a restrição e o pedido (já distribuídos no momento em que o Tambor foi elaborado), e sim, os estoques residentes nos demais recursos da empresa. A distribuição destes estoques deve agora acompanhar o Tambor que, como visto, não necessariamente estará seguindo a seqüência das datas dos pedidos.

Distribuídos os estoques, o sistema pode agora iniciar seu processo de retrocesso no tempo que deverá, necessariamente, começar pela última coisa que se vai fazer, ou seja, o último pedido (diferentemente do MRPII, como visto). se houver outra restrição na cadeia, um recurso sem capacidade excedente para repor o estoque antes da restrição, necessitar-se-á, em teoria, de um inventário infinito para se explorar efetivamente uma única restrição.

Ainda para Goldratt (1990), uma vez que os recursos restritivos não possuem qualquer capacidade protetora interna, estes devem ficar protegidos pela combinação do estoque colocado antes deles e pela capacidade protetora dos recursos que os abastecem. Existe uma compensação entre estes dois mecanismos de proteção. Menos capacidade protetora nos recursos de abastecimento exigirá níveis mais altos de inventário à disposição da restrição.

Desta forma, no exame da capacidade disponível, deve-se distinguir entre três, e não dois, segmentos de capacidade conceitual. O primeiro é a capacidade produtiva, o segmento necessário para a produção, a fim de se atender a demanda. O segundo segmento é a capacidade protetora, necessária como um escudo contra as variabilidades do sistema. Apenas o recurso restritivo não pos- 
sui capacidade protetora, pois este deve ser explorado. Qualquer capacidade remanescente, após levar-se em conta as capacidades produtiva e protetora, será considerada excesso de capacidade.

Para Goldratt (1990), quando se fala de capacidade protetora, tem-se sempre que considerar que um dos principais causadores do lead time de uma tarefa é a disponibilidade não imediata de recursos, isto é, determinada tarefa chega a um recurso não-restrição e este está ocupado trabalhando em outra tarefa necessária. Este fato pode tornar-se comum quando existe uma significativa flutuação no mix de produtos e, desta forma, um recurso pode apresentar picos de carga devido a estas flutuações.

Geralmente, o que se faz é adicionar uma capacidade permanente (investimento) mesmo que esta capacidade adicional seja, por definição, útil apenas parte do tempo. Uma saída para este problema seria fazer uso da compensação existente entre capacidade protetora e pulmão de tempo. Este pulmão variável é chamado pela TOC de Pulmão Dinâmico.

Basicamente, o que faz o Pulmão Dinâmico é variar o período de liberação de material para a fábrica com a finalidade de se evitar que um determinado recurso nãorestritivo, localizado antes do RRC, fique ocioso durante um longo período de tempo e extremamente sobrecarregado em outro. A função do Pulmão Dinâmico é equilibrar a carga neste recurso através de uma antecipação na data de liberação de material em relação à fixada anteriormente pelo pulmão de recurso original. Esta antecipação irá transferir para os períodos de ociosidade do recurso as sobrecargas de períodos posteriores.

A proposta do Pulmão Dinâmico é obter, a partir de uma previsão nas flutuações esperadas de carga, uma programação de liberação de materiais de acordo com estas flutuações. Isto permitiria uma redução no tempo em que o material deveria esperar a frente de um recurso e, assim, reduziria também o lead time total do sistema.

Para tanto, faz-se necessário reavaliar as estimativas iniciais dos pulmões de tempo. A partir da possibilidade de uso do conceito de Pulmão Dinâmico, o sistema de informação não deveria mais fazer uso da estimativa do lead time total da tarefa, já que a disponibilidade não imediata do recurso estaria sendo convenientemente minimizada pelo Pulmão Dinâmico. Necessita-se, portanto, estimar apenas o impacto que a parte fixa do pulmão de recurso, a qual deve considerar apenas fatores como quebra de máquinas, ausência de qualidade, etc., tem sobre o lead time da tarefa. Assim, ao se usar o conceito de Pulmão Dinâmico, todo o processo de subordinação e, portanto, de retrocesso no tempo, deve ser entendido como resultado da aplicação do Pulmão Dinâmico, e não mais das estimativas iniciais do pulmão de recurso.

\section{Diferenciando algumas situações de pico de carga}

Segundo Goldratt (1990) e Stein (1997), para um melhor entendimento do processo de subordinação, é necessário distinguir entre dois tipos de recursos nãorestritivos: aqueles localizados após o RRC (também chamados recursos de faixa vermelha) no roteiro de fabricação de um determinado pedido e aqueles localizados antes do RRC (recursos que alimentam o RRC).

Primeiramente, analisar-se-ão as atividades que geraram picos de carga em recursos localizados antes do RRC. As Figuras 6 e 7 ilustram, respectivamente, a posição do recurso com relação ao RRC e um possível perfil de carga para este recurso.

Ao se aplicar o conceito de Pulmão Dinâmico nesta situação, poder-se-ia chegar a uma situação próxima à representada pela Figura 8. Nota-se que os picos de carga foram transferidos para os vales localizados à esquerda deles. Transferir os picos para os vales localizados à direita não seria viável, pois implicaria numa redução do pulmão e, portanto, numa redução da proteção do programa do RRC. Transferir para a esquerda é a única alternativa.

Verifica-se, entretanto, que após padejar as cargas para a esquerda, surge um novo conflito, denominado por Goldratt (1990) de "pico de carga no primeiro dia". A existência destes picos deve ser combatida através de algumas medidas sugeridas pelo autor, como economizar

Figura 6: Recurso A com carga-máquina de $90 \%$ e localizado antes do RRC.

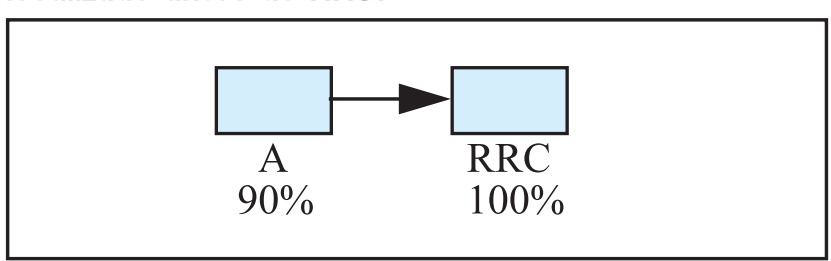

Figura 7: Exemplo de um possivel perfil de carga para o recurso $A$.

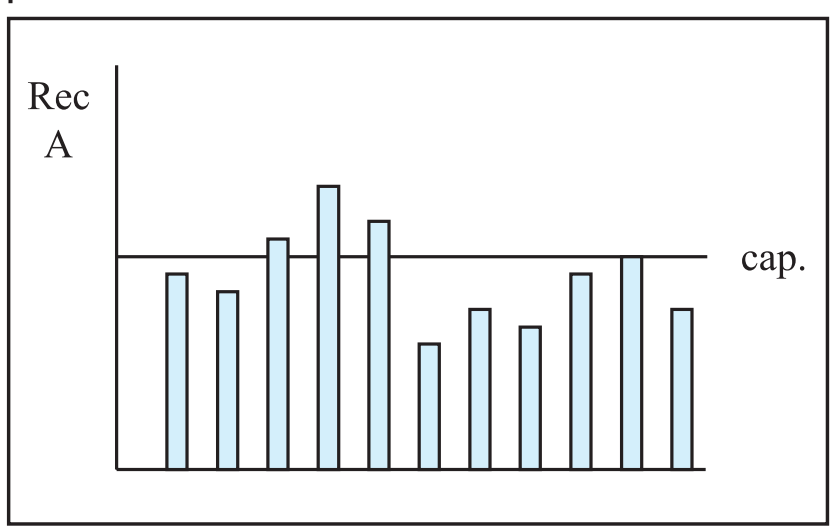


setups no recurso, fazer horas-extras ou usar metade do pulmão, deslocando cargas para a frente.

Neste último caso, o autor sugere que, ao se deslocar o pico de carga remanescente de primeiro dia para os vales localizados à direita, pode-se permitir que este deslocamento consuma até a metade do pulmão de recurso estabelecido. Tal conclusão, a qual parece ser de natureza empírica, ainda requer que os pedidos, cujos
Uma vez que o objetivo da fase de subordinação é fazer com que todos os recursos acompanhem o programa da restrição, não faz sentido propor-se, neste momento, qualquer tipo de alteração no programa do Tambor. Como padejar picos para a esquerda implica, nesta situação, uma alteração no Tambor, tal proposta está fora de cogitação. Quando ocorre, portanto, de recursos localizados após a restrição apresentarem um perfil de carga como o da Figura 9, a única alternativa que resta é permitir que os picos se desloquem para a direita, o que aconteceria naturalmente.

Nota-se que foi usado o termo permitir, pois muito pouco pode ser feito aqui em termos de programação, já que os momentos de chegada das tarefas no recurso já estão definidos pelo Tambor. Por outro lado, ao se permitir que os picos de carga sejam deslocados para a direita, estar-se-á consumindo o pulmão de mercado e, portanto, colocando em risco os prazos de entrega dos pedidos aos clientes. Novamente, o deslocamento para a direita deve consumir no máximo metade do pulmão, neste caso, do pulmão de mercado.

Uma consideração deve ser feita neste ponto. O perfil de carga das atividades de faixa vermelha é resultado da seqüência conferida aos blocos quando da construção

Figura 9: Recurso B com carga-máquina de $90 \%$ e localizado após o RRC.

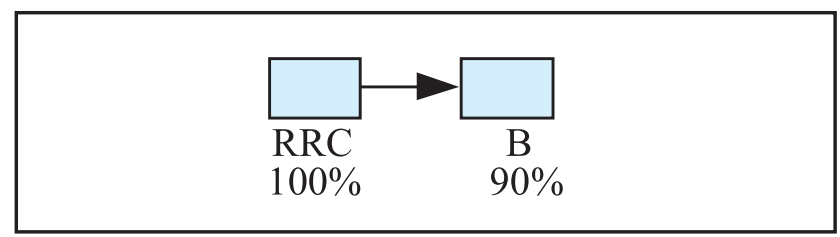

Figura 10: Exemplo de um possivel perfil de carga para o recurso $B$. deslocamento dos picos para a esquerda.
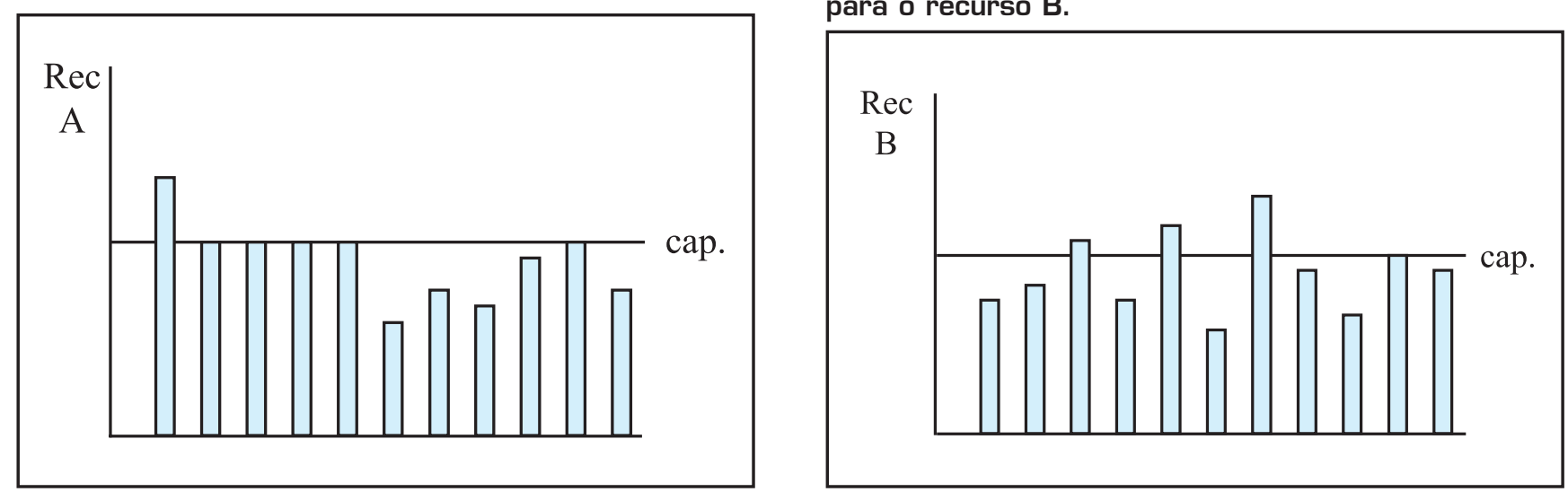
do Tambor, os quais, por sua vez, podem tanto estar à esquerda quanto à direita de suas posições originais. Portanto, ao se considerar a latitude máxima de deslocamento de uma atividade de faixa vermelha, deve-se levar em consideração o consumo ou o aumento do pulmão de mercado quando da elaboração do Tambor. Por fim, se ainda houver picos de carga, deve-se optar por horas-extras, descarregamento da carga para outro recurso ou adiamento do pedido.

Há, no entanto, uma maneira de se permitir um deslocamento para a esquerda mesmo em tarefas localizadas em faixas vermelhas: reduzir o tamanho dos lotes de transferência dos recursos localizados entre o RRC e o recurso em questão. A proposta, sugerida por Goldratt (1990), é fazer com que as peças sejam transferidas para o próximo recurso no roteiro antes que seu lote de processamento seja finalizado, ou seja, que se faça uso de lotes distintos para produção e transporte. Tal decisão anteciparia a chegada das tarefas no recurso B da Figura 9, o que equivaleria a padejar para a esquerda sem se alterar o Tambor. Se ainda assim estas medidas forem insuficientes para se eliminar os conflitos presentes, tal recurso deve ser declarado como restrição e é dada permissão para se reprogramar a restrição primária.

\section{Identificando e explorando uma nova restrição: reiniciando o ciclo}

Caso a etapa de subordinação tenha identificado uma nova restrição, o ciclo deve ser reiniciado, buscando-se a geração de um novo Tambor para a fábrica, o qual agora deve incorporar as novas restrições identificadas. Deve-se atentar que a quarta etapa (Elevação da restrição) somente seria alcançada quando todas as restrições tivessem sido identificadas e convenientemente exploradas.

Para Goldratt (1990), declarar outra restrição de recurso significa que este também deverá ser protegido com um pulmão, o que eleva o nível de inventário da fábrica. Também, o risco de perda de Ganho com duas restrições de recurso declaradas é maior, já que basta que uma delas falhe, ou fique desabastecida, para que o Ganho da empresa caia. Por estas razões, o autor considera que todo o esforço deve ser feito para que se evite a declaração de uma nova restrição de recurso. Vale dizer que, se mais de um recurso estiver com sobrecargas acima da metade do pulmão, será selecionado como a nova restrição da fábrica aquele que estiver mais sobrecarregado.

Declarada uma nova restrição de recurso, deve-se construir um quadro de ruínas para esta nova restrição. Para tal, serão considerados dados o Tambor original, o pulmão de expedição e apenas a metade do pulmão de recurso quando a operação de um recurso restritivo estiver abastecendo outro. O sistema deve então computar "o que" e "quando" esta nova restrição tem que executar, supondo disponibilidade infinita. cer. No entanto, tais conflitos estão agora relacionados com o programa para a restrição original (Tambor original), já que um RRC alimenta o outro. Para lidar com estes conflitos, há a necessidade de se usar o conceito de hastes de tempo (GOLDRATT, 1990; SIMONS et al., 1996), que está fora do escopo deste texto.

\section{CONSIDERAC̣ÕES FINAIS}

As discussões que se sucederam tiveram como objetivo possibilitar à comunidade acadêmica e empresarial um melhor entendimento do método Tambor-Pulmão-Corda e ver eliminadas algumas falsas premissas em relação a ele. Do que foi apresentado, pode-se concluir os seguintes pontos, os quais estão resumidos na Tabela 1 a seguir:

a) A TOC é um conjunto de conceitos que extrapolam o software OPT e mesmo o método TPC. A TOC atualmente é vista como uma ampla filosofia gerencial, fundamentada na lógica de que todo sistema deve ser administrado em função do papel exercido pela(s) sua(s) restrição(ões). O TPC deve ser entendido como parte da TOC, ou como uma aplicação da TOC nas questões da manufatura.

b) Não é mais correta a afirmação que os procedimentos heurísticos sugeridos pela TOC, para lidar com situações de programação da produção em recursos restritivos, são propriedades dos criadores do sistema e sobre os quais o usuário deve apenas confiar cegamente. Ainda que esta tenha sido uma possível verdade nos idos dos desenvolvimentos e aplicações iniciais do software OPT, tal afirmação deixa de encontrar respaldo na realidade atual. Todos os detalhes aqui apresentados, e outros que podem ser encontrados em Goldratt (1990), Stein (1997) ou Simons et al. (1996), desfazem qualquer dúvida neste sentido.

c) Em Goldratt (1988), são apresentados alguns aspectos relevantes do software OPT, explicando em detalhes o 
Quadro 1: Comparação entre a visão usual e os resultados identificados na pesquisa.

\begin{tabular}{|c|c|c|}
\hline ASPECTOS & VISÃO USUAL OPT/TPG & RESULTADO DA PESQUISA TPC \\
\hline $\begin{array}{l}\text { Compreensão da } \\
\text { abordagem TOC }\end{array}$ & $\begin{array}{l}\text { Considera a TOC como sinônimo do } \\
\text { OPT e limitada a aspectos de } \\
\text { programação da produção }\end{array}$ & $\begin{array}{l}\text { A TOC é vista como uma filosofia gerencial } \\
\text { que explora as questões de manufatura }\end{array}$ \\
\hline Acessibilidade ao sistema & Sistema fechado (caixa preta) & Algoritmos disponíveis na literatura \\
\hline Sistema de PCP & $\begin{array}{l}\text { Sinônimo do software OPT, sem } \\
\text { ênfase nos aspectos de controle da } \\
\text { produção }\end{array}$ & $\begin{array}{l}\text { Metodologia TPC para planejamento e } \\
\text { programação da produção e gerenciamento } \\
\text { do pulmão para controle da produção }\end{array}$ \\
\hline Programação do RRC & Finita para frente & Finita para frente e para trás \\
\hline $\begin{array}{l}\text { Programação dos } \\
\text { recursos não-restritivos }\end{array}$ & $\begin{array}{l}\text { Infinita para frente nos recursos após } \\
\text { o RRC e infinita para trás nos } \\
\text { recursos anteriores ao RRC }\end{array}$ & Sempre para trás \\
\hline
\end{tabular}

funcionamento dos módulos HALT, BRAIM e SERVE. Do conteúdo daquele artigo e do aqui apresentado, notase que o método TPC não pode mais ser considerado como sinônimo de OPT. Percebe-se, por exemplo, que em Goldratt (1990) não há nenhuma referência a alguns módulos principais do antigo OPT, como HALT, BRAIM ou SERVE. De fato, como comentado em Ptak \& Schragenheim (2004, p. 24), o método TPC, juntamente com a abordagem de Gerenciamento de Pulmão, vieram para substituir o OPT.

d) Costuma-se afirmar que a sistemática de programação para o recurso restritivo segue uma lógica de programação finita e para frente. Como aqui foi visto, ainda que a programação seja finita e se inicie a partir do primeiro pedido a ser entregue, o procedimento para seqüenciamento das tarefas no RRC não pode ser considerado nem para frente e nem para trás, já que ambos os sentidos são utilizados, mesmo que de uma maneira bastante singular.

e) As operações, inclusive montagem, que vêm na seqüência das operações realizadas pelo RRC não são, ao contrário do que geralmente se afirma, programadas para frente, a partir das datas estabelecidas pelas operações na restrição. Como visto, toda a programação dos recursos não-restritivos é feita na etapa de subordinação, a qual deve corresponder a um processo de efetivo retrocesso no tempo, a partir das datas dos pedidos e descontados os pulmões de tempo correspondentes. Além disso, ainda que fora do escopo principal deste artigo, observou-se aqui que, segundo a ótica do TPC de retrocesso no tempo, mesmo os sistemas que seguem a lógica MRP/MRPII não efetuariam, efetivamente, uma programação para trás.

A TOC, a partir de sua abordagem TPC, vem proporcionando bons resultados àqueles que dela fazem uso (NOREEN et al., 1996 e SALE \& INMAN, 2003). Em sua grande maioria, tais resultados advêm muito mais da aplicação de alguns conceitos fundamentais propostos para planejamento e programação da produção e explorados neste texto, do que propriamente do uso do software OPT. De fato, há atualmente muitos sistemas computacionais baseados na TOC, inclusive brasileiros, como o Drummer APS, da empresa Linter Sistemas. Em Correa et al. (2001, p.357-358), pode-se encontrar uma relação de sistemas de programação com capacidade finita, dentre os quais o Preactor, I2, The Goal System, Ressonance, entre outros, são fundamentados na TOC. Entender estes conceitos com a devida profundidade é, portanto, essencial para uma efetiva compreensão dos potenciais benefícios que por eles podem ser proporcionados. 
BLACKSTONE JR., J. H. The theory of constraints - a status report. International Journal of Production Research, v. 39, n. 6, p. 1053-1080, 2001.

CORREA, H; GIANESI, I.G.N; CAON, M. Planejamento, Programação e Controle da Produção MRPII/ERP: conceitos, uso e implantação. São Paulo: Atlas, 2001.

GOLDRATT, E.M. Corrente Crítica. São Paulo: Nobel, 1998.

Computadorized shop floor scheduling. International Journal of Production Research, v. 26 n. 3, p. 443-455, 1988.

Haystack Syndrome Sifting information out of the data ocean. North River Press, 1990.

GOLDRATT, E.M.; COX, J. A meta: um processo de aprimoramento contínuo. São Paulo: IMAM, 1986.
GOLDRATT, E.M.; FOX, R.E. A corrida. São Paulo: IMAM, 1989.

GOLDRATT, E.M.; SCHRAGENHEIM, E.; PTAK, C.A. Necessary but not sufficient - A Theory of Constraints Business Novel. The North River Press, 2000.

NOREEN, E.; SMITH, D.; MACKEY, J.T. A Teoria das Restrições e suas implicações na contabilidade gerencial. São Paulo: Educator, 1996.

PTAK, C.A.; SCHRAGENHEIM, E. ERP: tools, techniques, and applications for integrating the supply chain. St. Lucie Press, 2004.

SALE, M.L.; INMAN, R.A. Surveybased comparison of performance and change in performance of firms traditional manufacturing, JIT and TOC. International Journal of Production Research, v. 41, n. 4, p. 829$844,2003$.
SIMATUPANG, T.M.; WRIGHT, A.C.; SRIDHARAN, R. Applying the theory of constraints to supply chain collaboration. Supply Chain Management: An International Journal, v. 9 , n. 1 , p. $57-70,2004$

SIMONS JR; J.V.; SIMPSON III, W.P.; CARLSON, B.J.; JAMES, S.W.; LETTIERE, C.A.; MEDIATE JR., B.A. Formulation and solution of the drum-buffer-rope constraint scheduling problem (DBRCSP). International Journal of Production Research, v. 34, n. 9, p. 2405-2420, 1996.

SPENCER, M.S.; COX, J.F. Optimum Production Technology (OPT) and the Theory of Constraints (TOC): analysis and genealogy. International Journal of Production Research, v. 33, n. 6, p. 1495-1504, 1995.

STEIN, H. An investigation into the fundamentals of critical chain project scheduling. International Journal of Project Management, v. 19, p. 363-369, 2000.
STEIN, R.E. The Theory of Constraints: Aplications in Quality and Manufacturing. New York: Marcel Dekker, Inc., 1997.

UMBLE, E. J.; UMBLE, M. Integrating the Theory of Constraints into Supply Chain Management. Proceedings of the 33rd annual Decision Sciences Conference, San Diego, CA, p. 479-484, 2002.

UMBLE, M.M.; SRIKANTH, M.L. Synchronous Manufacturing: principles for world class excellence. Cincinnati: South-Western, 1996.

YUAN, K.; CHANG, S.; LI, R. Enhancement of Theory of Constraints replenishment using a novel generic buffer management procedure. International Journal of Production Research, v. 41, n. 4, p. 725-740, 2003.

- Sobre o autor

\section{Fernando Bernardi de Souza}

Universidade Metodista de Piracicaba - UNIMEP

Prof. Dr. Programa de Pós-Graduação em Engenharia de Produção

Endereço: Rod. Sta. Bárbara/Iracemápolis, Km 1

13450-000 - Sta Bárbara d'Oeste - SP

Fone: (019) 3124-2304 / (019) 3124-1767

Fax: (019) 3455-1361

E-mail: fbsouza@unimep.br 